\title{
Integrating Solid Freeform Manufacturing with Relief Creation Software
}

\author{
Chua C.K.
}

Lecturer, School of Mechanical and Production

Engineering, Nanyang Technological University,

Singapore 2263, 65-7994897 (P), 65-7911859 (F),

MCKCHUA@NTUVAX (EM)

\begin{abstract}
The integration of a colour scanner, 3-dimensional CAD/CAM system and Stereolithography Apparatus (SLA) provided a powerful means of building art to part. Artwork such as Chinese characters, human faces or flowers can be input by a scanner, converted into 3-D reliefs within a CAD/CAM system and built using the Stereolithography Apparatus (SLA). In this article, the effectiveness of such an integrated system is illustrated with 3 examples.
\end{abstract}

\section{Keywords}

Art-to-Part, SLA, Scanner, CAD/CAM, Reliefs

\section{INTRODUCTION}

There are presently numerous commercially-available software for product design for a particular range of industries which include ceramics, glassware, bottle making, both plastic and glass, jewellery, packaging, food processing, for moulded products and products produced from forming rolls and badges, and embossing rollers (Chua, 1993 and Lee, 1992). All of these industries share a common problem: most of their products have elements of complex engraving or low relief on them. Traditionally, such work is carried out by skilled engravers either in-house, or more often by a third-party sub-contractor, working from 2D artwork. This process is costly, open to unwanted misinterpretation of the design by the engraver and most importantly, lengthens the time of the design cycle.

The CAD/CAM revolution has boosted the production and the performance of many industries everywhere for the past 15 years (Lee, 1993). However, its 
applications in the above industries are still at their infancy stage. Prototyping is still very much a manual process which relies largely on the skills of an experienced craftsman who uses handtools such as a small chisel to carve and shape the model out of a plaster block. Little attention has been focused on the use of quick and accurate rapid-prototyping equipment for building prototypes in this industry.

The use of CAD/CAM and Stereolithography Apparatus (SLA) reduces the time required for design modifications and improvement of prototypes. The steps involved in the art to part process include the following:

- Scanning of artwork

- Generation of surfaces

- Generation of 3D relief

- Wrapping of relief on surfaces

- Converting triangular mesh files to STL file,

- $\quad$ Building of model by the SLA

\section{SCANNING OF ARTWORK}

The function of scanning software is to automatically or semi-automatically create a $2 \mathrm{D}$ image from $2 \mathrm{D}$ artwork. It would normally be applied in cases where it would be too complicated and time consuming to model the part from a drawing using existing CAD techniques. Figure 1 shows the $2 \mathrm{D}$ artwork of a series of Chinese characters and a roaring dragon.

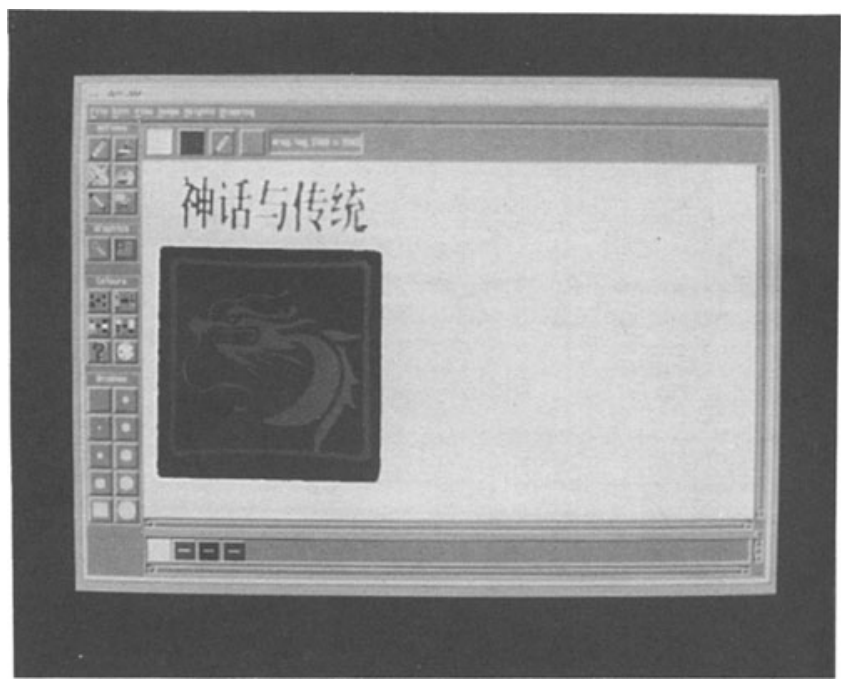

Figure $12 \mathrm{D}$ artwork. 


\section{GENERATION OF SURFACES}

The shape of a part is generated to the required shape and size in the CAD system for model building. A triangular mesh file is produced automatically from the 3D model. This is used as a base onto which the relief data is wrapped and later combined with the relief model to form the finished part.

\section{GENERATION OF 3D RELIEFS}

The next stage in creating the 3D relief is to assign to each colour in the image a shape profile. There are various fields which control the shape profile of the selected coloured region, namely, the overall general shape for the region, the curvatures of the profile (convex or concave), the maximum height, base height, angle and scale. There are three possibilities for the overall general shape; a plane shape profile will appear completely flat, whereas a round shape profile will have a rounded cross section and lastly, the square shape profile will have straight angled sides. Figure 2 illustrates the various shapes of the 3D reliefs. For each of these shapes, there is an option to define the profile as either convex or concave. The square and round profiles can be given a maximum height. If the specified shape reaches this height, it will 'plateau' out at this height giving in effect a flat region with rounded or angled corners, depending on whether a round or square shape was selected for the overall profile respectively. Figure 3 illustrates the 3D relief of an artwork.

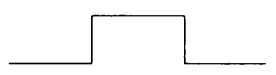

Flat profile

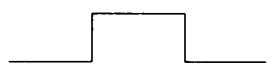

Flat profile with base height

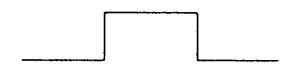

Flat profile with base height and maximum height

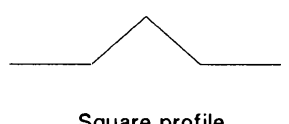

Square profile
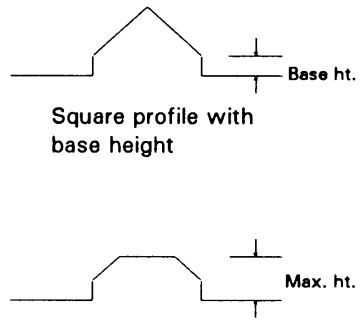

Square profile with base height and maximum height
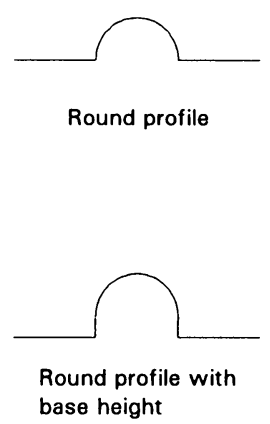

Round profile with base height and maximum height

Figure 2 Various shapes of the 3D relief. 


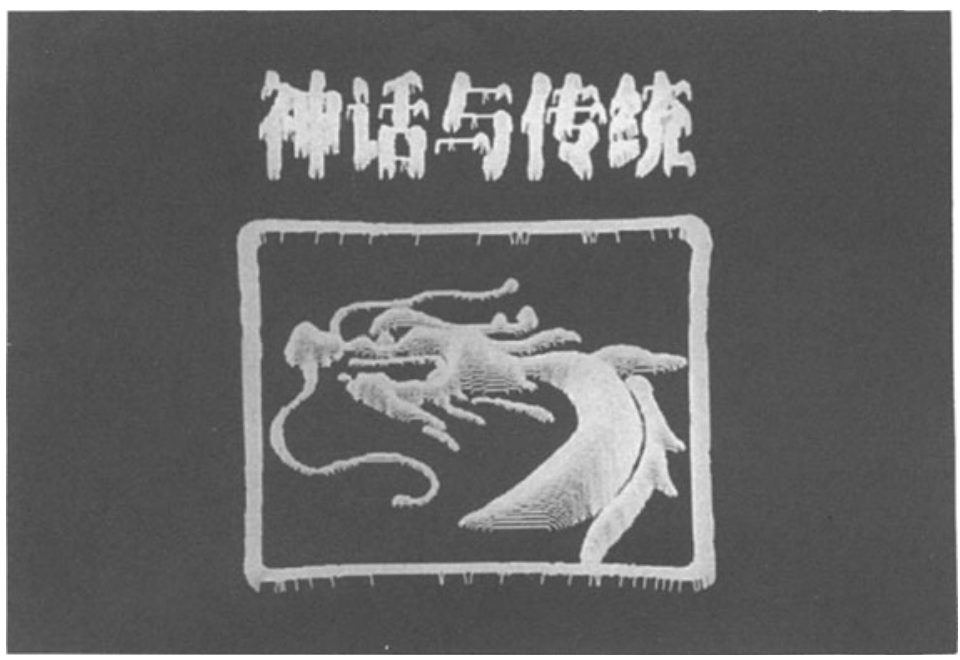

Figure 3 3D relief of an artwork.

\section{WRAPPING OF RELIEF ON SURFACES}

The $3 \mathrm{D}$ relief is next wrapped onto the triangular mesh file generated from the object's surfaces. This is a true surface wrap and not a simple projection. The wrapped relief is also converted into triangular mesh files. The triangular mesh files can be used to produce a $3 \mathrm{D}$ model suitable for colour shading and machining. The two sets of triangular mesh files, of the relief and the part shape, are automatically combined. The resultant model file can be colourshaded and used by the SLA to build the prototype.

\section{CONVERTING TRIANGULAR MESH FILES TO STL FILE}

The STL format is originated by 3D System Inc. as the input format to the SLA, and has since been accepted as the de facto standard of input for Layeredmanufacturing systems (Fidoora, 1991, Mueller, 1992 and DeAngelis, 1991). Upon conversion to STL, the object's surfaces are triangulated, which means that the STL format essentially consists of a description of inter-joining triangles that enclose the object's volume. The triangular mesh files are also triangulated surfaces, however, of a slightly different format (see figure 4). Therefore, an interface programme written in Turbo-C language was developed for the purpose of conversion. The converted triangular file adheres to the standard STL format as in figure 5. It has the capability of handling triangular files of huge memory size. 
DUCT 5.2 TRIANGLE BLOCK P 18 AUG 1993 21.43.28

*

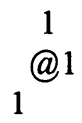

Figure 4 The original triangular file format.

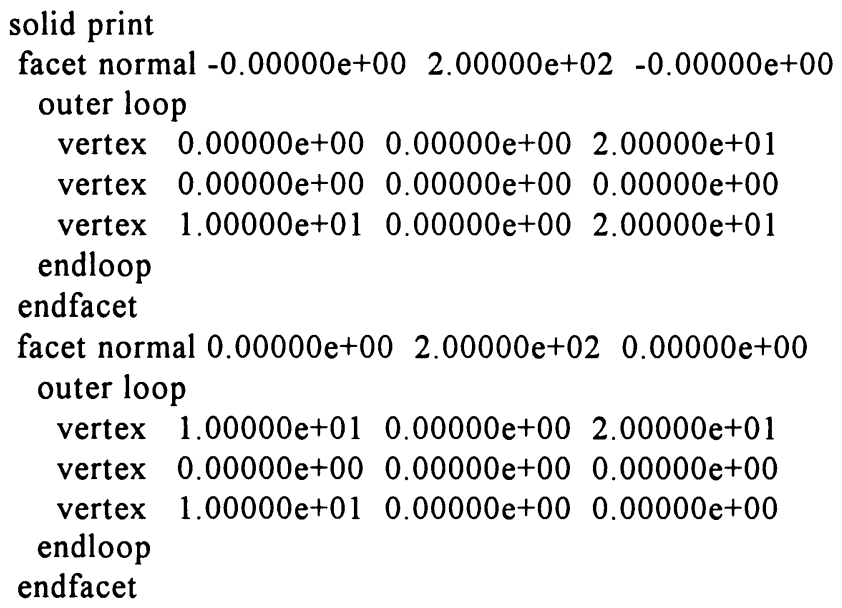

Figure 5 The converted triangular file to follow the STL format. 


\section{BUILDING OF MODEL BY THE SLA}

Californian company 3D System Inc., pioneered the Solid Free Manufacturing (SFM) technologies when they released their commercial SFM system in December 1988 - the SLA-250 model of their StereoLithography Apparatus (SLA) (Fidoora, 1991 and Mueller, 1992). Stereolithography works by using a low-power Helium-Cadmium laser or an Argon laser to scan the surface of a vat of liquid photopolymer which solidifies when struck by a laser beam. The SLA makes use of a variety of photopolymers with different properties suited for different requirements. The properties of the cured photopolymers should allow SLA prototypes to be used for making soft tools like rubber moulds for mass production. Research has shown that feasible rubber moulds can be made from SLA-produced jewellery rings (Lee, 1993). The SLA is capable of a $0.125-\mathrm{mm}$ minimum layer thickness and an accuracy of within $0.5 \%$.

\section{CASE STUDIES}

Three case studies are selected to illustrate the significant advantages of using the proposed art to part technique over the conventional tools and processes. These case studies are done to cover various types of artwork designs including animals, a human face, flowers as well as Chinese characters (see figure 6), and at the same time to show the feasibility of replacing the current plaster mould prototype with the resin model prototype. Alongside the advantages obtained in adopting the use of the proposed prototyping technique, the case studies also revealed shortcomings which provide scope for future work.

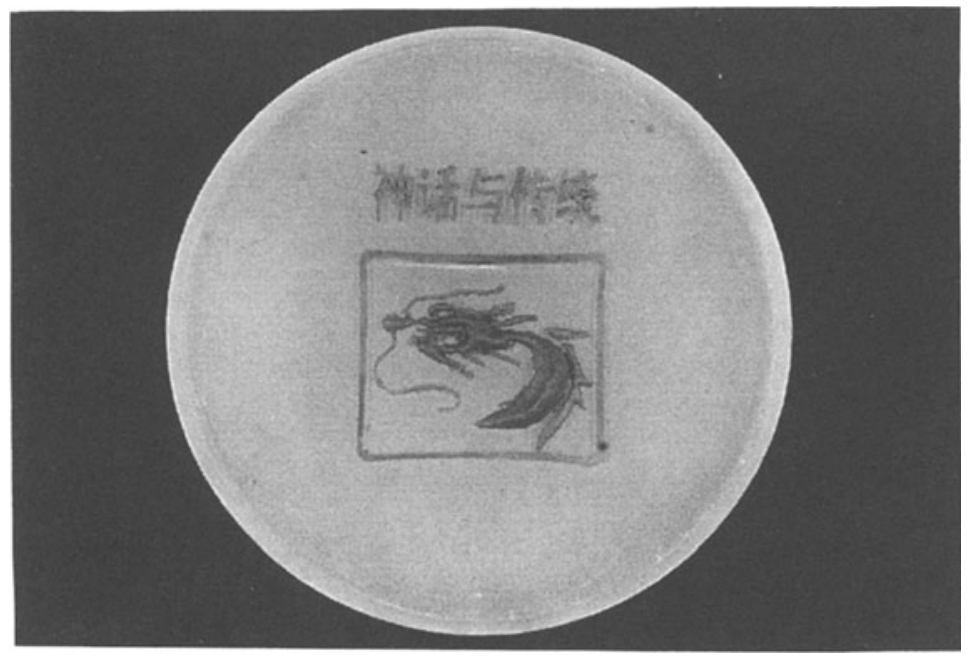

Figure 6 Resin prototype of the Chinese characters and roaring dragon. 


\section{ADVANTAGES OF THE INTEGRATED PROCESS}

The integration of the scanner, the CAD/CAM system and the SLA provides a list of specific advantages to the art to part process as given below:

\subsection{It saves time}

The existing technique of hand-carving takes about two weeks to complete a plaster mould. However, relief can be created in the CAD/CAM system in two hours' time and the prototype will be ready for examination in the next morning after going through the SLA. The time to market has become a competitive issue in the need to prototype quickly (Wood, 1990, Brown, 1991 and Poindexter, 1991).

\subsection{It is easy to amend}

There is often a need to amend the design of the prototype. Serious amendments will result in discarding of the plaster mould and doubling of the time needed to produce a model. The CAD/CAM system allows changes to be done quickly and easily and rebuilding of the model is also a simple task.

\subsection{It is easy to master and apply}

The whole system is relatively user friendly and the procedures for generating relief are short and simple. There is also a high potential in further extending the application into other industries.

\section{CONCLUSION}

The CAD/CAM software allows the formation of complicated and time consuming reliefs on models such as jewellery, ceramics tableware, pewter ware, etc. to be semi-automatically or automatically created. The software provides realistic viewing function to see the colour shaded final model and permits amendments to be made easily. Experiments on building models using the SLA have been carried out to study the application of the relief generating software system. Three models, the Chinese Legend and Tradition, the human face and the orchid, were built and examined. It was found that substantial amount of polishing work is needed to improve the surface finish of the resin models. The major advantage of this prototyping technique is the ability to create more prototypes for less time and cost. 


\section{ACKNOWLEDGEMENT}

The author acknowledges the industrial sponsorship of Delcam (Singapore) for this project.

\section{REFERENCES}

Brown, A. S. (1991), Rapid prototyping. Part without tools, Aerospace America, 29 (8).

Chua C. K., Hoheisel W., Keller G. and Werling E. (1993), Adapting decorative patterns for ceramic tableware, Computing and Control Engineering Journal, 4 (5).

DeAngelis, F. E. (1991), Laser-generated 3D prototypes, Laser in Microelectronic Manufacturing, San Jose, CA, USA, Sep. 10-11.

Fidoora, J. C. (1991), Stereolithography models - the keystone for limited production models, 49th Annual Technical Conference - ANTEC '91, May 59.

Lee H. B., Ko M. S. H., Gay R. K. L., Leong K. F. and Chua C. K. (1992), Using computer-based tools and technology to improve jewellery design and manufacturing", International Journal of Computer Applications in Technology, 5 (1), 72-80.

Lee H. B. (1993), Computer-aided and manufacturing for the jewellery industry, a thesis for the degree of Master of Engineering in Nanyang Technological University.

Mueller I. (1992), Stereolithography. A rapid way to prototype die castings, Die Casting Engineer, 36 (3).

Poindexter, J. W. (1991), Rapid prototyping in an integrated product development environment, 1991 SAE Aerospace Atlantic, Dayton, OH, USA, Apr. 22-26.

Wood, L. (1990), Rapid prototyping. Uphill, but not moving, Manufacturing System, 8 (12).

\section{BIOGRAPHY}

Chua Chee Kai is a lecturer with the School of Mechanical and Production Engineering in Nanyang Technological University, Singapore. He is a member of WG5.3 of TC5 of IFIP and is the Singapore Representative for TC5. He is also currently the President of the Institute of Industrial Engineers, Singapore. 